\title{
A Good Partner in Sleeping: A Research on Customer Value Regarding Mattresses
}

\author{
Yu-Ling Lin, Ya-Cing Jhan, and Hong-Wen Lin
}

\begin{abstract}
We spend one-third of our lifetime sleeping, so a good sleep is undoubtedly, an indicator of our quality of life. To guarantee peaceful sleep at night, high quality mattress is an essential element of what we lie on as more and more people suffer from lifestyle diseases such as anxiety, depression, and cardiovascular disorders. In this study, the means-end chains approach and hard laddering questionnaires based on laddering theory were used to explore the key attributes and values noted by mattress buyers, and the "AttributeConsequence-Value" relationships were processed into hierarchical value map to elaborate the hierarchical value of subjects on the mattresses. A hundred and twenty-two valid questionnaires were collected, and eleven attributes, fourteen consequences and nine values were obtained by categorization using content analysis method. Elasticity, price, and special materials are the three most welcomed attributes, and the improve sleep quality, best value and high practicality are the best consequences for respondents. In terms of values, security, fun and enjoyment in life and self-fulfillment are the ultimate values to be realized, suggesting that besides the fundamental requirements, customers expect more from the mattress they use.
\end{abstract}

Index Terms - Mattresses, Sleep quality, Means-end Chains, Hard laddering, Customer value.

\section{INTRODUCTION}

The level of national income has increased in recent years due to the high level of prosperity and the vigorous development in exports, which drive the consumption power and increase attention on the quality of life. However, sleep is the primary crucial factor for improving the quality of life. Having a good night's sleep will help restore energy and enhance the restorative functions of the body [1]-[2]. Conversely, poor sleep quality is a precursor to many physical and psychological diseases [3]. People spend one third of their time sleeping, so mattresses play a critical role. Selecting a suitable mattress will bring comfortable and healthy sleep quality. In addition to providing a comfortable sleep, the concept that a good mattress can promote health and prevent disease is gradually gaining attention. In the future, the perception and concept of healthy behavior will be promoted through health education [4].

The development trend for mattress materials range from the early wood, vines, straw mats, to the recent springs,

Published on December 31, 2020.

Yu-Ling Lin, Professor, Department of Business Administration, National Chin-Yi University of Technology, Taiwan (R.O.C.).

Ya-Cing Jhan, Ph.D. Candidate, Department of Business Administration, National Taiwan University of Science and Technology, Taiwan (R.O.C.).

Hong-Wen Lin, Associate Professor, Department of International Trade, Chinese Culture University, Taiwan (R.O.C.).

(corresponding e-mail: woodylin34@hotmail.com) memory foams, latex, silicon, pocket-springs and the latest multi-functional mattresses. This development trend indicates that mattresses are no longer intended just for sleep and will be designed to satisfy more diverse needs of life in the future.

There is ample literature focusing on mattresses satisfying the need for sleep, but whether or not there are still potential demands yet to be discovered is a topic worthy of exploration. In this study, the researcher has employed the Laddering Theory to investigate what benefits such potential demands can bring to users. The researcher was even more eager to explore what are the ultimate values pursued by users. During the product strategy formulation process, the researcher adopted the Means-end Chains theory to analyze the mattress attribute results valued by the users and the values created by such results. The "attribute-result-value" structure constructed by the users was used to render the Hierarchical Value Map. This map is used to explain the relationships between the users and the mattress attributes, consequences, and values; and to serve as a basis for product R\&D and strategy formulation reference for manufacturers. To understand how the users think based on their ultimate inner values, the research objectives of this study are as follows: (1) Explore the attributes valued by the mattress users when using mattresses. (2) Explore the relationship between the Attributes - Consequences - Values structured by mattress users. (3) The goal of this study is to explore the ultimate values pursued by mattress users.

\section{THEORETICAL BACKGROUND}

\section{A. Sleep Quality}

The definition of sleep quality refers to the comprehensive opinions made by individuals based on the relevant factors that directly or indirectly affect sleep and then measure the different individual demand satisfaction levels [3]. Past literature primarily focuses on three major aspects: quality, quantity, and indirectly related factors that affect sleep. First, quality refers to the individuals' sense of adequate sleep and their satisfaction. Second, the measurement aspects are the hours of sleep, sleep efficiency and the length of pre-sleep period. Finally, indirectly related factors include sleeping posture, ambient light [5], sleeping habits [6], eating habits [7], and work fatigue [8].

There is ample literature related to sleep quality. Many domestic and foreign studies used different growth stages as the primary research distinction to investigate the relevant variables that may affect sleep quality in each growth stage. Topics for such studies include pre-school child development [5], [9], sleep disorders in children and 
adolescents [10], factors affecting sleep for college students [4], the effects that work and workplace-related factors have on sleep [11]-[12], and healthy sleep for the elderly [7], [13], which show different research results.

There are two methods to treat sleep quality problems in medicine: drug treatment and non-drug treatment. The current medical system still primarily uses medication to improve insomnia [14], which can be effective within a short time for patients suffering from insomnia. However, clinical trials indicated that the curative effect would decrease over time, making patients addicted to medications due to long-term use and there is also the risk of side effects [15]-[17]. There are numerous sleeping medicines developed abroad. The earliest sleeping medicines include Barbiturates and Chloral-hydrate, but they have been replaced by Benzodiazepines. Benzodiazepine is an effective and safe insomnia treatment medicine. In addition to aiding sleep, it can also alleviate anxiety, relax muscles, and prevent spasms. In terms of non-drug treatment to improve sleep quality, there were over 1.7 billion prescriptions issued in the United States in 1989 to treat and alleviate insomnia or sleep disturbances according to a study conducted by [18]. However, medication abuse may render the drug ineffective and increase the dependence on the medication, which in turn becomes a burden for the body. Therefore, in addition to improving sleep quality via medicines, using non-pharmacological methods such as regular exercises and psycho-cognitive behavioral therapies to improve sleep and life quality have become the latest hot topics. Regular exercises can improve sleep quality and reduce sleep disorders [19]-[22]. Progressive muscle relaxation can reduce sleep latency and wake-up time after falling asleep. It can also improve sleep quality in terms of total sleep hours and sleep satisfaction [19]-[20].

A review of domestic and foreign literature indicated that mattresses are rarely included as a non-drug treatment factor affecting sleep quality. So, the researcher of this study explored the ultimate values of mattresses for users and explored what other values do people expect from a mattress in addition to being a basic sleeping tool. The results of this study can serve as a reference for product and marketing strategy development by the industry.

\section{B. Means-end Chains theory}

Consumers will assign certain meanings based on their thoughts regarding products, services, or purchase behaviors. When connected, these meanings can develop into different paths and levels. Therefore, [23] has integrated the concepts of [24]-[27] to propose the Means-end Chains (MECs) theory. "Means" refers to the activities or product functions that consumers are exposed to. "End" is the result after contact. It can also be described as the state of value reached by consumers such as a sense of accomplishment, satisfaction or belonging. MECs model as shown in Fig. 1.

MECs are composed of three levels: Attributes, Consequences and Values [28]. During the process of purchasing goods or services, users will consider the features of the goods or services that they perceive [29]. Such features are also called attributes. Product attributes can be felt and include concrete attributes and abstract attributes.

Users sometime make their purchase decisions based on the consequences or benefits brought by the products [28]. Consequences include the benefits that users desire and the risks that they want to avoid. The goods or services will provide a more specific or direct experience for users after purchase or utilization. Consequences are divided into functional consequences such as taking a shower to clean the body or turning on the lights to obtain illumination, and a more abstract is physiological consequence that generally refer to the users' psychological perceptions such as wearing a popular brand clothing can make one be more attractive [30].

Ultimately, the users investigate the values brought by the goods or services. [31] proposed a list of values closely related to the daily life of users, which includes nine items such as security, self-respect, sense of accomplishment, selffulfillment, excitement, well-respected, fun and enjoyment in life, sense of belonging, and warm relationships with others. Moreover, from the cognitive perspective, users will use attributes to generate results in order to achieve values and important life goals. Values can be divided into instrumental values based on preference or behavioral cognition and terminal values according to the heart's desire to become the final state of existence [23]-[24].

\section{MethodolOGY}

\section{A. Laddering Theory}

The Laddering Theory [32] is often adopted to detect MECs. The main purpose is to guide users to connect the attributes, consequences, and values for the products that they desire in order to effectively understand and analyze the links between the product "Attributes-ConsequencesValues" for the users; and then comprehensively construct the MECs link contents. The so-called "ladder" refers to using one-on-one in-depth interviews and direct elicitation methods to use the results triggered by a particular product attribute preference as well as the target values brought about by the consequences to investigate the link between them [33].

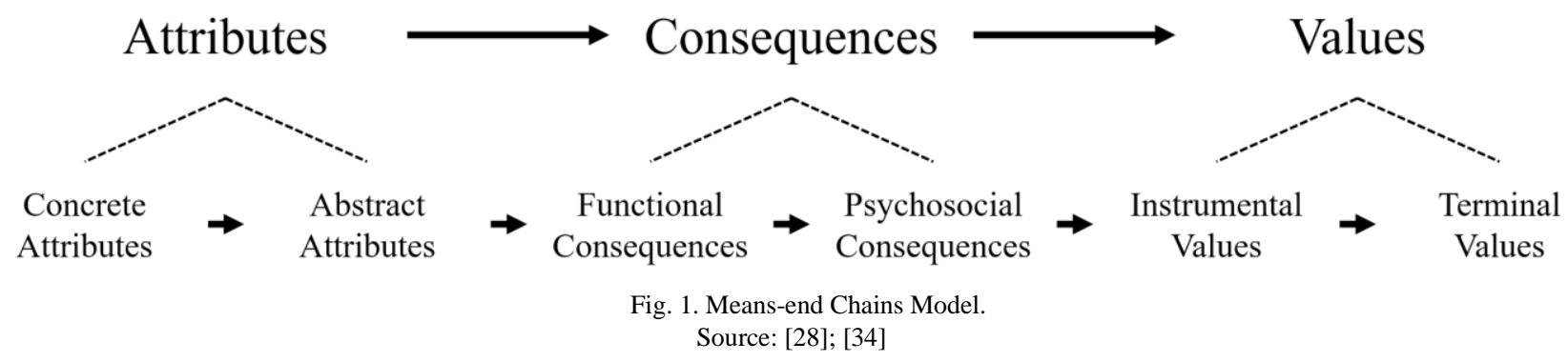


The Laddering Theory can be divided into Hard Laddering that restricts one level of answer at a time and Soft Laddering that does not restrict the answers [35]. The goal is to explore the target values pursued by users. This researcher of this study used the rigid ladder questionnaire design, distribution, and collection method to explore the links between the attributes, consumption consequences, values for mattress products and analyzed their relationships. After completing the interviews, the Content Analysis method was used to calculate the number of linked relationships between the variables and input them into the Implication Matrix. An example of linked relationship is "Attributes-Consequences" and "Consequences-Values." Finally, the linked relationship of each variable in the Implication Matrix is plotted into a Hierarchical Value Map [32].

\section{B. Sample Analysis}

According to past literature, the adequate sample size for the rigid ladder method is approximately 30 to 300 [34], [36]-[38]. To meet this recommendation, a total of 168 questionnaires were issued. After eliminating the invalid questionnaires, a total of 122 valid questionnaires were collected, which is an abundantly adequate sample number. Most of the questionnaire recipients were friends and relatives. So, the interviewees were more willing to relax their guards and truthfully describe the "attribute-resultvalue" based on the impacts that their mattresses have on them. The majority of interviewees are women, accounting for $68.03 \%$. The sample age group is mostly between $41-50$ years of age. The majority of interviewees are married housewives, accounting for $84.43 \%$. Sample structure as shown in Table 1. The sequential order for the main questionnaire contents of this study is: (1) What attributes did you value when you select, buy, or use a mattress? (2) What consequences did the attributes you value bring you? (3) What values did the consequences you obtained bring you?

\section{RESULTS}

\section{A. Coding Analysis}

A total of 11 attributes, 14 consequences and 9 values were extracted from the questionnaires via content analysis. The number of mentions for each variable is summarized in Table 2. Elasticity, price, special materials, appearance design and product specifications are the top five attributes valued by the interviewees. Elasticity refers to the elastic force and softness of the mattress and whether it has a pocket-spring structure. This is the most important attribute for mattress buyers. Price refers to the price level and reasonableness when the customer buys a mattress. It is the second ranking attribute. Special materials refer to the raw materials used to make the mattress, whether or not they are natural, and whether or not the surface would generate fuzz balls after use. The appearance design attribute covers style, color, fashion, pattern, and shape. Finally, customers would consider if the mattress they like has the proper size, thickness, and weight. Such considerations are classified as product specifications in this study.
Improve sleep quality, best value, high practicality, strengthen health care and meet psychological demands are the top five ranking user attributes linked to the consequences. The researcher of this study has classified improve sleep quality, feels very comfortable and comfort level as the consequences of improve sleep quality, which are the most crucial consequences for mattress users. Best value refers to the budget, worth, good quality and low price, money saving, affordable, as well as personal economic and cost considerations mentioned by the interviewees. Moreover, high practicality refers to durability, no need to change often, practical, long lasting, as well as quality assurance and guarantee. The researcher of this study has classified body protection, prevent back pain, too soft or too hard is bad for health, non-allergenic, will not cause rashes and other health-related descriptions under strengthen health care.

TABLE I: SAMPLE STRUCTURE

\begin{tabular}{lccc}
\hline \multicolumn{1}{c}{ Demographic variable } & Item & Amount & Percentage \\
\hline Gender & Male & 39 & 31.97 \\
& Female & 83 & 68.03 \\
\hline Age & Less than 30 & 21 & 17.21 \\
& $31 \sim 40$ & 12 & 9.84 \\
& $41 \sim 50$ & 53 & 43.44 \\
& $51 \sim 60$ & 31 & 25.41 \\
& More than 61 & 5 & 4.10 \\
\hline Marital status & Single & 19 & 15.57 \\
& Married & 103 & 84.43 \\
\hline Number of mattress purchases & 1 & 32 & 26.23 \\
& 2 & 30 & 24.59 \\
& 3 & 28 & 22.95 \\
& 4 & 11 & 9.02 \\
& 5 & 4 & 3.28 \\
& More than 6 & 17 & 13.93 \\
\hline
\end{tabular}

\begin{tabular}{|c|c|c|c|}
\hline Level & Variables & Amount & Total \\
\hline \multirow[t]{11}{*}{ Attributes } & A01 Appearance design & 46 & 398 \\
\hline & A02 Price & 70 & \\
\hline & A03 Brand & 31 & \\
\hline & A04 Breathability & 16 & \\
\hline & A05 Professional service & 7 & \\
\hline & A06 Product specifications & 37 & \\
\hline & A07 Production site & 7 & \\
\hline & A08 Service life & 22 & \\
\hline & A09 Elasticity & 94 & \\
\hline & A10 Health function & 10 & \\
\hline & A11 Special materials & 58 & \\
\hline \multirow{14}{*}{ Consequences } & C01 Meet psychological demands & 29 & 398 \\
\hline & C02 Best value & 72 & \\
\hline & C03 Improve sleep quality & 119 & \\
\hline & C04 Visual aesthetics & 27 & \\
\hline & C05 Relieves pressure & 12 & \\
\hline & C06 Strengthen health care & 29 & \\
\hline & C07 High practicality & 39 & \\
\hline & C08 Convenient to organize at home & 10 & \\
\hline & C09 High product safety & 19 & \\
\hline & C10 Good warranty system & 4 & \\
\hline & C11 Enhanced trust level & 14 & \\
\hline & C12 Meet the sleep demands & 9 & \\
\hline & C13 Increase the joy of life & 12 & \\
\hline & C14 Increase the willingness to buy & 3 & \\
\hline \multirow[t]{9}{*}{ Values } & V01 Security & 124 & 398 \\
\hline & V02 Self-respect & 8 & \\
\hline & V03 Sense of accomplishment & 46 & \\
\hline & V04 Self-fulfillment & 48 & \\
\hline & V05 Excitement & 1 & \\
\hline & V06 Well-respected & 17 & \\
\hline & V07 Fun and enjoyment in life & 99 & \\
\hline & V08 Sense of belonging & 46 & \\
\hline & V09 Warm relationships with others & 9 & \\
\hline
\end{tabular}


The top ranking ultimate values obtained by the mattress users are sense of security, enjoy life and self-fulfillment. The researcher of this study has classified trustworthiness, familiarity, steadfastness, integrity, etc., under the sense of security value. It has the highest number of links. In addition, enjoy life has the second highest number of links, which brings the users a sense of happiness, joy, fulfillment, hope for the future, motivation, feeling special and good mood. Finally, the researcher of this study has classified desire satisfaction, pursuit of perfection, self-affirmation, and doing something meaningful under the self-fulfillment value.

\section{B. Implication Matrix Analysis}

The original data of the questionnaire were transformed using the Variable Code Classification Table to present the hierarchical link relationships. After calculating the link relationships based on the paths mentioned in the questionnaires, an Implication Matrix was rendered as shown in Table 3. The results of the Implication Matrix analysis indicated that the 122 valid questionnaires provided a total of 398 ladders. On average, each interviewee mentioned 3.26 ladders. The interviewees created a total of 796 links with an average of 6.52 links per interviewee.

\section{Hierarchical Value Map Analysis}

If all of the links are rendered into the hierarchical value map (HVM), it would become too complex to identify the links that the mattress users' value. Therefore, the researcher of this study multiplied the number of samples by the Cutoff Value of 5\% according to [39]'s suggestion and used it as the basis for screening to render the HVM. This study has 122 valid samples. Therefore, the cut-off value is 6.1 , which is used as the basis for screening to render the HVM. After deleting the values below the cut-off point of 6.1 in the Implication Matrix, the mattress HVM rendered is shown in Fig. 2.

i. Elasticity \& special material-improve sleep qualitysense of security \& enjoy life
Elasticity is the most important attribute for purchasing a mattress. Users believe that the level of mattress hardness will affect the quality of sleep. Therefore, buying a mattress with the appropriate elasticity can help to improve sleep quality (62 links). Once sleep quality is improved, the user will feel a sense of security (49 links). Good quality sleep would also promote positive emotions such as being more motivated during chores and feeling happier, which further achieves the value of fun and enjoyment in life (42 links). In addition, the consequences brought about by the special materials attribute is improve sleep quality (27 links), which satisfies the users' ultimate values of sense of security (49 links) and fun and enjoyment in life (42 links).

ii. Price - best value - sense of achievement \& selffulfillment

Price brings three different implications to users. Some users believe they should buy more expensive mattresses so that they can sleep with a peace of mind. Some believe they should buy cheaper mattresses to just meet the most basic needs and the last group of users believe that fair price is the most important thing. They would also consider the purchase if a higher price leads to better quality. This is how best value ( 58 links) is linked. When users consider the price, they hope to buy an equivalent value mattress, which in turn satisfies their sense of achievement (21 links) and self-fulfillment (18 links).

iii. Appearance design - visual aesthetics - enjoy life \& self-fulfillment

Appearance design is one of the mattresses buying attributes for users. Appearance design affects the users' visual comfort. Therefore, the appearance attraction, beauty, aesthetics, good looks and preference mentioned by the interviewees were classified as results of visual aesthetics (27 links). These results satisfy personal desires and happiness and ultimately achieve the values of fun and enjoyment in life (11 links) and self-fulfillment (9 links).

TABLE III: IMPLICATION MATRIX RESULTS

\begin{tabular}{|c|c|c|c|c|c|c|c|c|c|c|c|c|c|c|c|c|c|c|c|c|c|c|c|c|}
\hline Coding & $\mathrm{C} 01$ & $\mathrm{C} 02$ & $\mathrm{C} 03$ & $\mathrm{C} 04$ & $\mathrm{C} 05$ & $\mathrm{C} 06$ & $\mathrm{C} 07$ & $\mathrm{C} 08$ & $\mathrm{C} 09$ & $\mathrm{C} 10$ & C11 & C12 & $\mathrm{C} 13$ & C14 & V01 & V02 & V03 & V04 & V05 & V06 & V07 & V08 & V09 & Total \\
\hline $\mathrm{A} 01$ & 11 & 1 & 2 & 27 & & & & 4 & & & & & 1 & & & & & & & & & & & 46 \\
\hline A02 & 4 & 58 & 1 & & & & 3 & & & & & 3 & & 1 & & & & & & & & & & 70 \\
\hline A03 & 1 & & & & 1 & & 11 & & 6 & 2 & 10 & & & & & & & & & & & & & 31 \\
\hline A04 & & 1 & 10 & & 2 & 2 & & & 1 & & & & & & & & & & & & & & & 16 \\
\hline A05 & 2 & & & & & & 1 & & & 2 & 1 & & & 1 & & & & & & & & & & 7 \\
\hline A06 & 2 & 2 & 14 & & 1 & 1 & & 5 & 1 & & & 5 & 6 & & & & & & & & & & & 37 \\
\hline A07 & & & & & & 1 & 3 & & 3 & & & & & & & & & & & & & & & 7 \\
\hline A08 & & 4 & 1 & & & 1 & 11 & & 3 & & 1 & & 1 & & & & & & & & & & & 22 \\
\hline A09 & 3 & 3 & 62 & & 4 & 16 & 1 & & 1 & & & & 4 & & & & & & & & & & & 94 \\
\hline A 10 & 1 & & 2 & & 1 & 3 & 2 & & & & & & & 1 & & & & & & & & & & 10 \\
\hline A11 & 5 & 3 & 27 & & 3 & 5 & 7 & 1 & 4 & & 2 & 1 & & & & & & & & & & & & 58 \\
\hline C01 & & & & & & & & & & & & & & & 4 & 2 & 5 & 4 & & 2 & 7 & 4 & 1 & 29 \\
\hline $\mathrm{C} 02$ & & & & & & & & & & & & & & & 12 & 2 & 21 & 18 & & 6 & 10 & 3 & & 72 \\
\hline $\mathrm{C} 03$ & & & & & & & & & & & & & & & 49 & 1 & 4 & 2 & & & 42 & 18 & 3 & 119 \\
\hline C04 & & & & & & & & & & & & & & & 1 & & 2 & 9 & & & 11 & 4 & & 27 \\
\hline C05 & & & & & & & & & & & & & & & 1 & & 1 & & & 1 & 4 & 5 & & 12 \\
\hline C06 & & & & & & & & & & & & & & & 10 & & 2 & 1 & 1 & & 9 & 5 & 1 & 29 \\
\hline C07 & & & & & & & & & & & & & & & 17 & 1 & 7 & 5 & & 2 & 6 & 1 & & 39 \\
\hline $\mathrm{C} 08$ & & & & & & & & & & & & & & & 1 & 1 & 1 & 3 & & & 3 & 1 & & 10 \\
\hline C09 & & & & & & & & & & & & & & & 15 & & & 1 & & 1 & 1 & & 1 & 19 \\
\hline C10 & & & & & & & & & & & & & & & 3 & & & & & 1 & & & & 4 \\
\hline C11 & & & & & & & & & & & & & & & 5 & & 1 & 1 & & 3 & 1 & 2 & 1 & 14 \\
\hline $\mathrm{C} 12$ & & & & & & & & & & & & & & & 4 & & & & & & 2 & 2 & 1 & 9 \\
\hline $\mathrm{C} 13$ & & & & & & & & & & & & & & & 2 & & 1 & 4 & & 1 & 3 & 1 & & 12 \\
\hline C14 & & & & & & & & & & & & & & & & 1 & 1 & & & & & & 1 & 3 \\
\hline Total & 29 & 72 & 119 & 27 & 12 & 29 & 39 & 10 & 19 & 4 & 14 & 9 & 12 & 3 & 124 & 8 & 46 & 48 & 1 & 17 & 99 & 46 & 9 & 796 \\
\hline
\end{tabular}




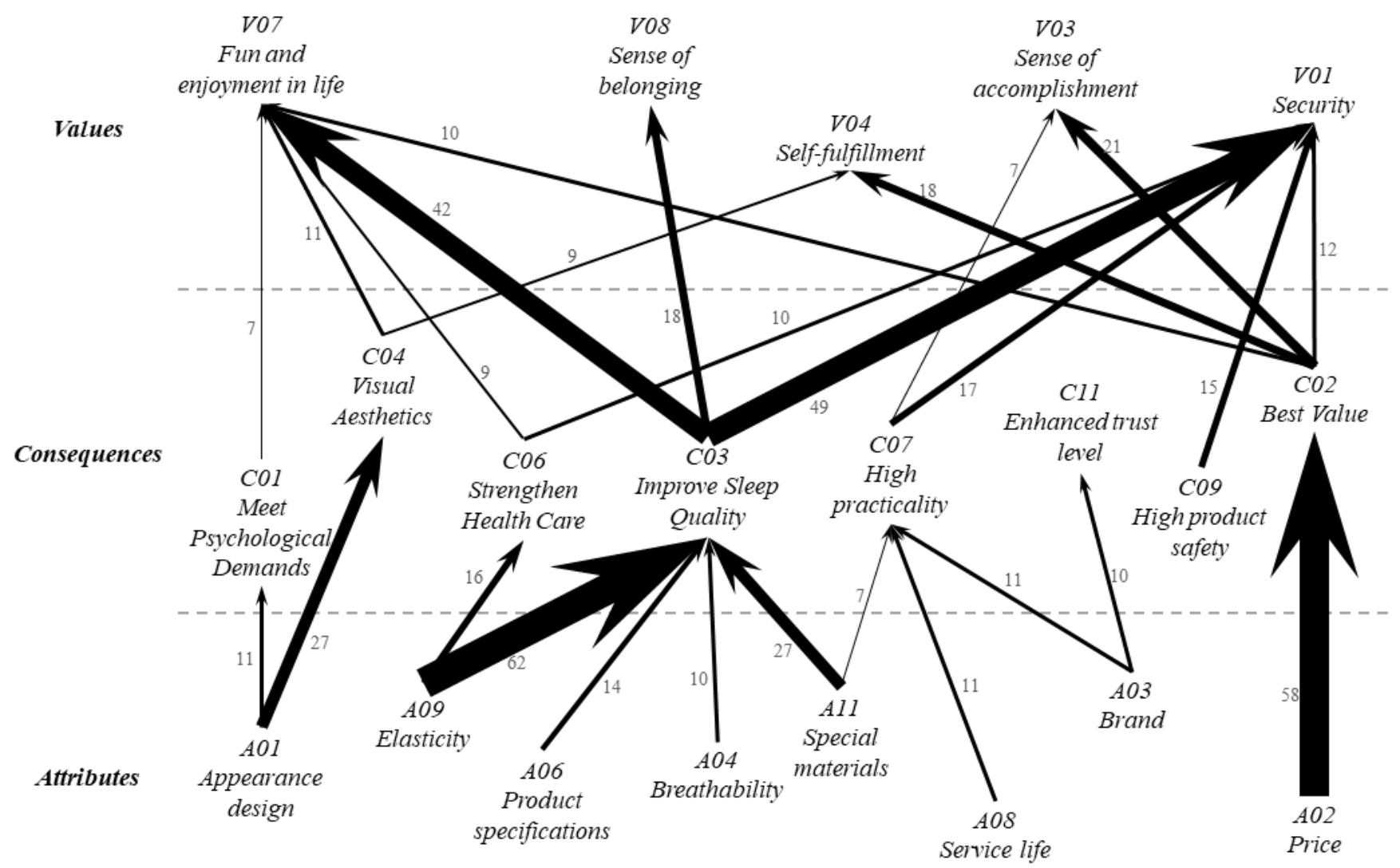

Fig. 2. HVM of Mattresses.

\section{CONCLUSIONS AND IMPLICATIONS}

\section{A. Conclusions}

Mattress users have different perceptions of mattress attributes due to different socioeconomic backgrounds, which create different consumption consequences and values. By using the HVM under the MECs framework, it is possible to analyze and discover the attribute-result-value chain relationship for mattress users and thereby propose clear guidelines for formulating product, price, channel, promotion and other sales strategies. The effort can help the decision makers to formulate effective strategies, achieve sales goals, provide products that consumers prefer and increase consumption value.

The researcher of this study found that the most often mentioned attribute is elasticity, which includes the level of hardness and bounciness. Elasticity determines the comfort of the mattress, so $77 \%$ of the interviewees have attached significant importance to this attribute. The majority of interviewees believe that harder mattresses offer better sleep. Price is the second most mentioned attribute. Most of the interviewees indicated that fair price is critical, and that they hope to buy high-quality products at a low price. Special materials are the third most mentioned attribute. The interviewees stated that they are more concerned about whether or not the mattress materials are natural and whether or not the surface would generate fuzz balls after use.

Improve sleep quality, best value, high practicality is the three most often mentioned consequences. $97.5 \%$ of the interviewees indicated that the goal of buying a suitable mattress is to improve sleep quality. The "best value" result is linked to the price attribute. It means that a customer can purchase a good quality mattress with equal value. Finally, the interviewees believe that mattresses should be durable. Therefore, the researcher of this study has classified descriptions such as durability, no need to be replaced all the time, practicality, long lasting, and quality assurance as the resultant benefits of "high practicality."

Purchasing a suitable mattress gives users a sense of trust, familiarity, steadfastness, integrity and thereby meeting the target value of satisfying the inner sense of security. Buyers tend have a sense of superiority, vanity, distinction, pride, glory and self-affirmation if they can select and purchase the mattress that they like, which in turn create the ultimate values of fun and enjoyment in life and self-fulfillment.

\section{B. Implications}

The researcher of this study has provided recommendations and descriptions below based on the mattress users' HVM to offer a development strategy reference for the mattress industry. The top target values focused by the mattress users are sense of security, fun and enjoyment in life, and self-fulfillment. These three target values should serve as the foundation of mattress design and development for mattress manufacturers.

Manufacturers should clearly label the mattresses' elasticity, safety design, production origin and special materials in detail in order to position their mattresses as trustworthy and high-integrity products. In addition to improving sleep and comfort, the interviewees also hope 
that the special material features can also achieve a health restorative effect during sleep. Therefore, it is recommended that additional health care functions should be considered during mattress R\&D. For example, water beds and farinfrared mattresses can further satisfy the target value of sense of security. Such products can tap into the potential needs of consumers and enhance the incentives to buy. Manufacturers can design trial experience activities for buyers before purchase to reduce the consumers' distrust and satisfy their sense of security for the product.

Manufacturers are recommended to design mattress advertisements using concepts and images of happiness and joyful life and strengthen the brand and appearance design. Moreover, health care functions should be added for mattresses so that they may be promoted as more than just for home use and can be positioned as gifts to transcend the traditional image of mattresses.

Manufacturers are recommended to design interactive websites to guide customers to learn the correct information for the mattresses that they desire and offer virtual space simulations to enable customers to plan the space layout for the bed and select the suitable mattress specification. The ability to select product specification and exterior design enables customers to feel a sense of self-affirmation and doing something meaningful, which in turn achieves the ultimate value of self-fulfillment.

\section{REFERENCES}

[1] K. Adam, I. Oswald, "Sleep helps healing," Br. Med. J., vol. 289, no. 24, pp. 1400-1401, 1984.

[2] J. Hasan, H. Urponen, L. Vuori, and M. Partinen, "Exercise habits and sleep in a middle-aged Finnish population," Acta Physiol. Scand., vol. 113, no. 574, pp. 33-35, 1988.

[3] D. J. Buysse, C. F. Renolds Ш, T. H. Monk, S. R. Berman, and D. J. Kupfer, "The pittsburgh sleep quality index: A new instrument for psychiatric practice and research," Psychiatry Res., vol. 28, pp. 193213, 1988.

[4] C. M. Becker, S. McMahan, J. J. Etnier, and R. Nelson, "The potency of health promotion versus disease prevention messages in a college population," Am. J. Health Stud., vol. 18, no. 1, pp. 26-30, 2002.

[5] G. J. Tortora, and B. H. Derrickson, Principles of anatomy and physiology, New York, NY: John Wiley and Son, 2010.

[6] W. B. Mendelson, "Sleep after forty," Am. Fam. Physician, vol. 29 no. 1 , pp. $135-139,1984$

[7] P. M. Becker, and A. O. Jamieson, "Common sleep disorders in the elderly: Diagnosis and treatment," Ge., vol. 47 no. 3, pp. 41-52, 1992.

[8] M. Kivistö, M. Härmä, M. Sallinen, and R. Kalimo, "Work-related factors, sleep debt and insomnia in IT professionals," Occ. Med., vol. 58, no. 2, pp. 138-140, 2008.

[9] C. Benedict, S. Dimitrov, L. Marshall, and J. Born, "Sleep enhances serum interleukin-7 concentrations in humans," Brain Behav. Immun., vol. 21 , no. 8, pp. 1057-1062, 2007

[10] X. C. Liu, Z. X. Sun, and M. Uchiyama, "Prevalence and correlates of sleep problem in Chinese school children," Sleep, vol. 23, pp. 1053 1062, 2000.

[11] A. Nakata, T. Haratani, and M. Takahashi, "Job stress, social support at work, and insomnia in Japanese shift workers," J. HUM. Ergol., vol. 30, pp. 203-209, 2001.

[12] A. Ota, T. Masue, N. Yasuda, A. Tsutsumi, Y. Mino, and H. Ohara, "Association between psychosocial job characteristics and insomnia: An investigation using two relevant job stress models-the demandcontrol-support (DCS) model and the effort-reward imbalance (ERI) model," Sleep Med., vol. 6 no. 4, pp. 353-358, 2005.

[13] M. S. Giron, Y. Forsell, C. Bernsten, M. Thorslund, B. Winblad, and J. Fastbom, "Sleep problems in a very old population: Drug use and clinical correlates," J. Gerontol. A Biol. Sci. Med. Sci., vol. 57 no. 4 pp. 236-240, 2002.

[14] G. D. Mellinger, M. B. Balter, and E. H. "Uhlenhuth, Insomnia and its treatment: Prevalence and correlates," Arch. Gen. Psychiatry, vol. 42, pp. 225-232, 1985.
[15] B. Riedel, K. Lichstein, B. A. Peterson, M. T. Epperson, M. K Means, and R. N. Aguillard, "A comparison of the efficacy of stimulus control for medicated and non-medicated insomniacs," Behav. Modif., vol. 22, pp. 3-28, 1998.

[16] M. J. Chambers, "Exercise: A prescription for a good night's sleep?" Phys. Sportsmed., vol. 19, no. 8, pp. 106-116, 1991.

[17] R. J. Hughes, and P. Badia, "Sleep-promoting and hypothermic effects of daytime melatonin administration in humans," Sleep, vol. 20, no. 2, pp. 124-131, 1997.

[18] R. R. Bootzin, and M. L. Perlis, "Nonpharmacologic treatments of insomnia," J. Clin. Psychol., vol. 53, pp. 37-40, 1992.

[19] C. M. Morin, J. P. Culbert, and S. M. Schwartz, "Nonpharmacological interventions for insomnia: A meta-analysis of treatment efficacy," Am. J. Psychiatry, vol. 151, pp. 1172-1180, 1994.

[20] D. R. R. Murtagh, and K. M. Greenwood, "Identifying effective psychological treatment for insomnia: A meta-analysis," J. Consult. Clin. Psychol., vol. 63, pp. 79-89, 1995.

[21] S. Hong, and J. E. Dimsdale, "Physical activity and perception of energy and fatigue in obstructive sleep apnea," Med. Sci. Sports Exerc., vol. 35, no. 7, pp. 1088-1092, 2003.

[22] T. Sato, S. Demura, T. Murase, and Y. Kobayashi, "Quantification of relationship between health status and physical fitness in middle-aged and elderly male and females," J. Sports Med. Phys. Fitness, vol. 45, no. 4, pp. 561-569, 2005

[23] J. Gutman, "A means-end chain model based on consumer categorization processes," J. Mark., vol. 46, no. 2, pp. 60-72, 1982.

[24] M. J. Rokeach, The nature of human values, New York, NY: The Free Press, 1973.

[25] S. Young, and B. Feigin, "Using the benefit chain for improved strategy formulation," J. Mark., vol. 39, no. 3, pp. 72-74, 1975.

[26] D. E. Vinson, J. E. Scott, and L. M. Lamont, "The roles of personal values in marketing and consumer behavior," J. Mark., vol. 41 no. 2, pp. 44-50, 1977.

[27] J. A. Howard, Consumer behavior: Application of theory. New York, NY: McGraw-Hill, 1977.

[28] J. C. Olson, and T. J. Reynolds, Understanding consumers' cognitive structures: Implications for marketing strategy, advertising and consumer psychology, Lexington: Lexington Books, pp. 77-90, 1983.

[29] T. J. Reynolds, C. Dethloff, and S. J. Westberg, Advancements in laddering, understanding consumer decision making: The means-end approach to marketing and advertising strategy, Hillsdale, NJ: Lawrence Erlbaum Associates, 2001.

[30] P. Valette-Florence, and P. B. Rapacchi, "Improvements in meansend chain analysis," J. Advert. Res., vol. 31, pp. 30-45, 1991.

[31] L. R. Kahle, Social values and social changes: Adaption to life in America. New York, NY: Praeger, 1983.

[32] T. J. Reynolds, and J. Gutman, "Laddering theory, method, analysis and interpretation," J. Advert. Res., vol. 28, no. 1, pp. 11-31, 1988.

[33] J. P., Peter, and J. C. Olson, Consumer behavior and marketing strategy (9thed). Boston, MA: Irwin/ Mcgraw-Hill, 2009.

[34] B. Walker, and J. C. Olson, "Means-end chains: Connecting products with self," J. Bus. Res., vol. 22, no. 2, pp. 111-118, 1991.

[35] K. G. Grunert, and S. C. Grunert, "Measuring subjective meaning structures by the laddering method: Theoretical considerations and methodological problems," Int. J. Res. Mark., vol. 12, no. 3, pp. 209$225,1995$.

[36] R. Pieters, H. Baumgartner, and D. Allen, "A means-end chain approach to consumer goal structures," Int. J. Res. Mark., vol. 5, pp. 227-244, 1995.

[37] P. Valette-Florence, "A causal analysis of means-end hierarchies in a cross-cultural context: Methodological refinements," J. Bus. Res., vol. 42, pp. 161-166, 1998.

[38] R. Zanoli, and S. Naspetti, "Consumer motivations in the purchase of organic food," Br. Food J., vol. 104, no. 8, pp. 643-653, 2002.

[39] C. E. Gengler, and T. J. Reynolds, "Consumer understanding and advertising strategy: Analysis and strategic translation," J. Advert Res., vol. 35, no. 4, pp. 19-33, 1995. 